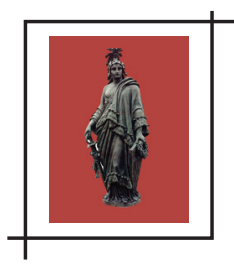

\title{
KANT E O LUGAR DO LIVRE-ARBÍTRIO
}

\section{Andrea Faggion ${ }^{1}$}

Resumo: 0 presente texto tem como objetivo apresentar algumas análises sobre o conceito de livre-arbítrio na filosofia kantiana. 0 conceito surge logo no contexto da solução das antinomias na Crítica da razão pura. Nesta obra, o autor aborda a questão a partir de uma distinção inicial interna ao conceito de causalidade segundo a natureza e causalidade pela liberdade. A causalidade pela liberdade, objetivo principal desta reflexão, se refere à possibilidade de um primeiro começo na ordem causal ou, em outras palavras, à possibilidade de que uma causa não seja, por sua vez, também um efeito, sendo então incondicionada. É nesta perspectiva que se insere o tema do livre-arbitrio para Kant.

Palavras-chave: Liberdade. Livre-arbitrio. Causalidade. Antinomias. Natureza.

No periodo crítico de Kant, o conceito de arbitrium liberum surge logo no contexto da solução das antinomias na Crítica da razão pura. Nesta obra inaugural do pensamento crítico, Kant aborda a questão a partir de uma distinção inicial interna ao conceito de causalidade: causalidade segundo a natureza e causalidade pela liberdade. A primeira, de que trata a célebre Segunda Analogia da Experiência, diz respeito à sucessão regular dos estados de uma substância e estabelece que todo evento é efeito de outro evento, o que, portanto, nos remete à busca da própria causa deste último e assim por diante. Já a causalidade pela liberdade se refere à possibilidade de um primeiro começo na ordem causal ou, em outras palavras, à possibilidade de que uma causa não seja, por sua vez, também um efeito, sendo então incondicionada. É nesta problemática que se insere o tema do livre-arbitrio para Kant. Ele nos diz que um arbítrio é sensivel na medida em que é afetado pela sensibilidade, mas há que se distinguir a mera influência da sensibilidade de uma necessidade causal provocada pela mesma. Neste último caso, o arbitrio é brutum ou animal. Porém, quando a ação não decorre necessariamente da sensibilidade e o agente, por conseguinte, possui a capacidade de se determinar a agir independentemente dela, isto é, quando a influência sensivel não é uma

1 - Mestra, doutora, pós-doutora em Filosofia pela Universidade Estadual de Campinas (Unicamp). Professora associada do Departamento de Filosofia da Universidade Estadual de Londrina (UEL).E-mail: andreafaggion@gmail.com 
condição necessária das ações, estamos falando de um arbitrium liberum. Sendo a causalidade livre definida nestes termos, precisamos saber qual o domínio de aplicabilidade deste conceito, ou seja, precisamos investigar se a liberdade será compatível com a natureza ou se fará parte de um discurso com uma semântica própria. Neste último caso, devemos determinar qual será este campo semântico próprio à liberdade. Nosso trabalho tem por foco a Crítica da razão pura, mas examina o desdobramento do problema em obras posteriores da filosofia crítica.

\section{LIBERDADE E NATUREZA NA CRÍTICA DA RAZÃO PURA}

Na Crítica da razão pura, a primeira preocupação de Kant quanto a nosso tema é distinguir e compatibilizar liberdade e natureza como duas espécies de causalidade. No domínio da natureza como intuições espaço-temporais determinadas por regras discursivas a priori, Kant não abre mão de um determinismo estreito. Toda mudança objetiva observável é uma sucessão de estados de uma substância e, como tal, precisa ser distinguida da sucessão de impressões sensíveis na consciência do observador. Em outras palavras, precisamos de um critério que nos permita distinguir entre a ocorrência de um evento no mundo objetivo e a ocorrência da apreensão de um fenômeno na consciência subjetiva, afinal, por alguma razão, se apreendemos sucessivamente os andares de um arranha-céu, nem por isso deixamos de atribuir simultaneidade aos mesmos.

A explicação de Kant é que atribuiriamos a sucessão aos próprios estados de uma substância, e não apenas à nossa percepção deles, quando uma regra causal determinasse como irreversivel a ordem da sucessão. Assim, abrir mão de tal regra seria o mesmo que abrir mão da possibilidade de uma ordem temporal objetiva. Temos então que a natureza, para Kant, só pode se constituir enquanto tal se expulsar a liberdade entendida como a geração de eventos que não tenham sido determinados por eventos precedentes. Por exemplo, se alguém comete um assassinato, há um momento t1 em que aquela ação não estava em curso e um momento t2 em que era praticada. Eu só poderei fixar objetivamente a posição temporal da ação, isto é, pensá-la como algo que, de fato, se deu no mundo, e não apenas em minha imaginação, se eu pensar tal ocorrência como tendo sido determinada a existir por uma ocorrência anterior, por exemplo, por uma paixão que se manifestou no sujeito. Obviamente, esta paixão não explica o surgimento da ação em determinado ponto do tempo se existiu desde sempre. Assim, ela própria é uma ocorrência que, para ter objetividade, precisa ser explicada por outra e assim por diante, de modo que nunca haja um primeiro começo da série causal.

Ora, se nos contentamos com o ponto de vista do observador que pretende explicar ações, não há problema algum com essa ausência de um primeiro começo na natureza. 0 problema 
se configura quando assumimos o ponto de vista de agentes que avaliam se devem ou não praticar determinadas ações. Fazer uma consideração do tipo equivale a pressupor que podemos praticar uma determinada ação, ou seja, gerar uma ocorrência no mundo objetivo independentemente da cadeia causal que nos precede. Pois bem, mas se só podemos pensar este agente como parte da natureza, então sua crença em um poder de agir "independentemente da coação por impulsos sensiveis" (KANT, 1997a, p. 434) precisa ser vista como uma ocorrência natural conectada a outras. Em suma, a exclusão da liberdade do domínio da natureza significaria a preponderância do discurso teórico sobre o discurso prático. É isto que Kant parece sintetizar nesta relevante passagem:

Facilmente se reconhece que, se toda causalidade no mundo dos sentidos fosse simplesmente natureza, cada acontecimento seria determinado por um outro, no tempo, segundo leis necessárias e, por conseguinte, como os fenômenos, na medida em que determinam o arbítrio, deviam tornar necessárias todas as ações como suas conseqüências naturais, a supressão da liberdade transcendental [o poder que um agente teria de começar uma ação] anularia simultaneamente toda a liberdade prática [independência do arbítrio frente à sensibilidade]. Porque esta pressupõe que, embora algo não tenha acontecido, teria, não obstante, devido acontecer e, portanto, a sua causa no fenômeno não era pois tão determinante a ponto de não haver no nosso arbítrio uma causalidade capaz de produzir, independentemente dessas causas naturais e mesmo contra o seu poder e influência, algo determinado na ordem do tempo por leis empíricas e, por conseguinte, capaz de iniciar completamente por si mesmo uma série de acontecimentos (KANT, 1997a, p. 463).

Neste momento ao menos, não ocorreu a Kant que a sensibilidade, não sendo, por si mesma, objetiva, poderia ser, paralelamente, determinada a partir de conceitos outros que não os teóricos, de forma a ser constituído um domínio ainda sensível para a aplicação de um discurso, mas não teórico. Colocando mais claramente, dados sensiveis espaço-temporais não são equivalentes a objetos empíricos em sentido kantiano. Só há um objeto empírico quando regras discursivas a priori são aplicadas a eles. Ademais, há dados sensiveis, como os sentimentos, que sequer contam para o discurso da explicação teórica, a menos que sejam eles próprios, objetos de intuição. Nesse sentido, um caminho que poderia ter se aberto a Kant seria a consideração da sensibilidade como passivel de determinação por uma outra ordem de conceitos, a saber, os práticos. Assim, uma mesma ação no mundo sensivel tanto poderia ser explicada naturalmente quanto julgada moralmente, conforme aplicássemos a ela conceitos teóricos ou práticos. Como a sensibilidade, por si só, não se coaduna especificamente a uma ou outra forma de discurso, sendo apenas maleável à atividade discursiva, não haveria incompatibilidade entre liberdade e natureza. 
Mas esta, que fique claro, não foi a saida kantiana, embora Kant, para resolver o problema, também julgue necessário apelar a um duplo ponto de vista ou diferentes perspectivas sobre as ações humanas. Ocorre que uma dessas perspectivas, para Kant, não será sensível. Um agente sensível e um agente determinado pela natureza serão uma e a mesma coisa, portanto, uma causa livre deve ser pensada como uma causa inteligivel, a saber, uma causa não submetida a condições espaço-temporais, o que Kant julga ser possivel desde que nos comprometamos com o idealismo transcendental, doutrina segundo a qual as formas espaço-temporais não pertencem às coisas consideradas em si mesmas, sendo, ao invés, formas de sua apreensão sensivel, de modo que todos os objetos espaço-temporais o são apenas relativamente às cognições que se tem deles:

\footnotetext{
[...] tendo estes fenômenos que ter por fundamento um objeto transcendental que os determina como simples representações, visto não serem coisas em si, nada impede de atribuir a este objeto transcendental, além da faculdade que tem de aparecer, também uma causalidade, que não é fenômeno, embora o seu efeito se encontre, ainda assim, no fenômeno (KANT, 1997a, p. 466).
}

Kant parece querer nos dizer que a simples noção de um fenômeno pressupõe algo que aparece e que não sabemos o que é em si. Este "algo" seria o objeto transcendental. Porém, como o objeto em geral, entendido em conformidade com o conceito crítico, não passa da unidade de uma síntese de dados sensiveis regulada a priori, já parece algo obscuro que se aplique o conceito de objeto para além da sensibilidade. Uma vez que o pensamento (a discursividade) se resume ao processamento de dados sensiveis, a simples especulação quanto à origem transcendental desses dados parece transcender os limites de todo significado possível. Impossivel ainda seria compreender o poder causal não esquematizável deste objeto transcendental no mundo sensivel.

De todo modo, a tese de Kant é que a ordem natural não seria perturbada por essa intromissão inteligível, porque o mesmo efeito não deixaria de ter também uma causa sensível, ou talvez devamos dizer que a mesma causa teria um caráter inteligível e um caráter empírico. Quando fazemos considerações práticas sobre nossas ações, nos colocamos do ponto de vista inteligível, quando queremos explicá-las teoricamente, nos colocamos do ponto de vista sensivel. A causalidade inteligível é o conceito com o qual Kant pretende escapar à dicotomia humeana entre acaso e necessidade natural. Nossas ações seriam imputáveis a nós por terem sido causadas por nosso arbítrio, mas não na medida em que o tomamos como fenômeno, pois, se fosse o caso, poderíamos ser apenas externamente livres, ao passo que esta liberdade de movimentos não conta para a responsabilidade moral.

Fazendo a liberdade prática repousar sobre o inteligível incognoscível, Kant se vê forçado a afirmar que só pode esclarecer, e não comprovar, o princípio de ação que ele, assim, decla- 
ra como meramente regulador. Na tentativa de tornar o conceito mais claro, o famoso exemplo utilizado é o da mentira maldosa, da qual "se investigam primeiro as razões determinantes que a suscitaram, para julgar em seguida como lhe pode [ao homem] ser imputada com todas as suas conseqüências" (KANT, 1997a, p. 476).

Adotando o primeiro ponto de vista, nos detemos no caráter empírico do mentiroso, com sua má educação, más companhias e má índole. Em resumo, procuramos condicionantes genéticos e ambientais de seu comportamento e os somamos aos motivos ocasionais. Mas, se a mentira é adjetivada como "maldosa", já está implícito que todas essas explicações serão colocadas entre parênteses.

\begin{abstract}
[...] se pressupõe que se podia pôr inteiramente de parte essa conduta e considerar a série passada de condições como não tendo acontecido e essa ação inteiramente incondicionada em relação ao estado anterior, como se o autor começasse absolutamente com ela uma série de conseqüências. Esta censura funda-se numa lei da razão, pela qual se considera esta uma causa que podia e devia ter determinado de outro modo o procedimento do homem, não obstante todas as condições empíricas mencionadas. E não se considera esta causalidade da razão simplesmente como concorrendo para aquela conduta, mas como completa em si própria, embora os móbiles sensiveis não Ihes sejam nada favoráveis, mas completamente adversos; a ação é atribuída ao caráter inteligivel do autor; e este é totalmente culpado no momento em que mente; por conseguinte, não obstante todas as condições empíricas da ação, a razão era plenamente livre, e este ato deve inteiramente imputar-se à sua omissão (KANT, 1997a, p. 476-477).
\end{abstract}

Analisando os pressupostos semânticos do discurso moral, Kant constata a necessidade de suspensão do discurso naturalista. Ele se julga autorizado a dar este passo que Hume recusou-se a dar em razão da novidade filosófica de seu idealismo transcendental. 0 problema é que, ao remeter a aplicabilidade do discurso moral a um domínio inteligível, tudo que Kant pode fazer é explicá-lo negativamente. Pisamos o terreno do insondável e do incompreensivel, afinal, como dar um significado, ainda que apenas prático, a um ato que não veio a ser e nem existiu desde sempre? Uma vez que minha atividade consciente (incluindo, portanto, meus raciocínios) é sempre temporal, seria o ato moral por excelência, em algum sentido, inconsciente? Não estaria Kant obrigado a reconhecer que, por mais que a validade do discurso racional seja atemporal, a atividade racional tem que se dar no tempo, como qualquer outra? Estaria ele deduzindo da necessidade de considerarmos os argumentos segundo um tempo lógico uma ordem genética numênica que teria o mesmo papel de um tempo histórico? Não seria isto a confusão de se tomar como concorrentes o tempo lógico e o tempo histórico? Certamente, a racionalidade não nos obriga à negação do tempo histórico e à busca de um sucedâneo numênico para ele, mas apenas ao reconhecimento de que 
nossas proposições, para serem válidas, devem ser arranjadas em uma ordem lógica que não se explica geneticamente. Parece que temos que aceitar, com Kant, que o discurso moral não cabe no domínio da natureza, mas sua tentativa de dissolver uma contradição entre conceitos pela dissociação de domínios semânticos não confere positividade alguma ao discurso moral, não Ihe confere um autêntico domínio de aplicabilidade. Pior ainda, parece alocar a atividade racional no reino do sobrenatural, onde os conceitos fundamentais (atos, objetos...) se dissolvem por completo.

Entretanto, o que vimos até aqui não é tudo que a Crítica da razão pura tem a nos dizer sobre liberdade. Passaremos agora brevemente pelo Cânon, mantendo em mente que, no contexto da Dialética, Kant (1997a) afirmou que a liberdade prática repousa sobre a liberdade transcendental e que esta não pode ser pensada por leis da experiência. Nesse sentido, o que causa perplexidade de modo especial no Cânon é a afirmação de que a liberdade prática pode ser demonstrada por experiência. A liberdade transcendental é dita simplesmente "um problema para a razão", por não poder ser pressuposta "empiricamente como um princípio de explicação dos fenômenos" (KANT, 1997a, p. 637). Neste momento, o livre-arbitrio é apenas uma faculdade de agir conforme representações, e não imediatamente conforme impulsos sensíveis: "possuímos um poder de ultrapassar as impressões exercidas sobre a nossa faculdade sensivel de desejar, mediante representações do que é, mesmo longinquamente, útil ou nocivo" (KANT, 1997a, p. 637). Com isso, aparentemente, poderíamos dizer que, malogrado ou bem-sucedido, teria sido em vão todo o esforço em defesa da liberdade na Dialética, pois, agora, a liberdade é compatível com a natureza e não haveria repercussão moral em tal afirmação.

Assim, diz Kant:

[...] saber se a própria razão, nos atos pelos quais prescreve leis, não é determinada, por sua
vez, por outras influências e se aquilo que, em relação aos impulsos sensiveis se chama li-
berdade, não poderia ser, relativamente a causas eficientes mais elevadas e distantes, por
sua vez, natureza, em nada nos diz respeito do ponto de vista prático (KANT, 1997a, p. 638).

Na mesma passagem, para o espanto do leitor da Dialética, a liberdade prática é citada como "uma das causas naturais", enquanto é dito que a liberdade transcendental, incompatível com a natureza e com a experiência, "mantém-se em estado de problema" e é "totalmente indiferente" (KANT, 1997a, p. 638). No Cânon, portanto, Kant não tem nenhum interesse em defender a possibilidade de uma atividade numênica, que nem Deus sabe onde e quando se daria, bastaria para a moral a constatação de que não agimos sempre por impulso, mas também por deliberação. Supostos atos de uma causa numênica não contariam nem para a teoria e nem para a prática, mas apenas para a especulação.

Mera especulação sem maior relevância também seria uma investigação quanto às datas de composição do Cânon e da Dialética, afinal, como tem sido reconhecido, um homem que 
reúne textos contraditórios e os envia para publicação também seria um homem capaz de escrever textos contraditórios em um mesmo periodo. Nosso propósito então deve ser a compreensão conceitual da tensão interna ao pensamento de Kant, que oscila entre uma posição compatibilista entre liberdade e natureza, em que a primeira é apenas mais uma causa natural, e uma posição incompatibilista, em que a imputabilidade moral exigiria a exclusão da liberdade do domínio da natureza. Da mesma forma, Kant parece hesitar entre a autonomia, a defesa da pureza da lei moral ante a sensibilidade, e a heteronomia, a suposição da necessidade de sensificação (aqui, naturalização) do motivo moral.

Como expressão de uma defesa da autonomia, temos a seguinte passagem:

\begin{abstract}
[...] há, realmente, leis morais puras que determinam completamente a priori o fazer e o não fazer (sem ter em conta os móbiles empíricos, isto é, a felicidade), ou seja, o uso da liberdade de um ser racional em geral e que estas leis comandam de uma maneira absoluta (não meramente hipotética, com o pressuposto de outros fins empíricos) e, portanto, são, a todos os títulos, absolutas (KANT, 1997a, p. 640-641).
\end{abstract}

Dito isso, Kant ainda advoga em prol do poder que a razão pura teria que ter para se realizar historicamente, pois se ela proclama o que deve acontecer, como vimos em outro contexto, devemos pensar que os mesmos atos podem acontecer. Curiosamente, mesmo após o que tinha sido dito há pouco, ele acrescenta que os atos livres da razão não podem ser produzidos por leis naturais e, ainda assim, "possuem uma realidade objetiva" (CRP, A 808, B 836). Devemos supor que seria esta a realidade dos feitos históricos da razão, mas, a esta altura, fica bastante difícil saber como devemos pensar a experiência cujos princípios de possibilidade Kant atribui à razão em seu uso moral. Ele parece preocupado em esclarecer este ponto quando, na alínea subsequente, nos fala de um mundo moral, que é apenas inteligivel, mas teria influência real no mundo sensivel:

\begin{abstract}
A idéia de um mundo moral tem, portanto, uma realidade objetiva, não como se ela se reportasse a um objeto de uma intuição inteligivel (não podemos conceber objetos deste gênero), mas na medida em que se reporta ao mundo sensivel, considerado somente como um objeto da razão pura no seu uso prático e a um corpus misticum dos seres racionais que nele se encontram, na medida em que o livre-arbitrio de cada um, sob o império das leis morais, tem em si unidade sistemática completa tanto consigo mesmo, como com a liberdade de qualquer outro (KANT, 1997a, p. 641-642).
\end{abstract}

Kant aqui se aproxima muito da exposição de um domínio sensivel não natural para a interpretação de conceitos práticos. É dito que não se pode conceber objetivamente um mundo inteligível, exceto como ideia que se realiza no mundo sensível, moralizando-o. 
Porém, este mundo sensivel parece ser novamente equiparado ao mundo natural, quando Kant introduz a distinção entre as condições de apreciação da lei moral e as condições para que ela possa ter vigência. Esta distinção, inclusive, parece surgir com o propósito de resolver a tensão entre autonomia e heteronomia. Explicando as condições sob as quais podemos efetivamente agir sob a lei moral, Kant parece admitir interesses privados como condições necessárias a toda ação humana:

\begin{abstract}
É necessário que toda a nossa maneira de viver esteja subordinada a máximas morais; mas é ao mesmo tempo impossivel que isto aconteça, se a razão não unir à lei moral, que é uma simples idéia, uma causa eficiente, que determina, conforme a nossa conduta relativamente a essa lei, um resultado que corresponda precisamente, seja nesta vida, seja numa outra, aos nossos fins supremos. Portanto, sem um Deus e sem um mundo atualmente invisivel para nós, mas esperado, são as magníficas idéias da moralidade certamente objetos de aplauso e de admiração, mas não mola propulsora de intenção e de ação (KANT, 1997a, p. 644).
\end{abstract}

A partir desta breve reconstrução da filosofia moral kantiana tal qual exposta na Crítica da razão pura, arriscariamos concluir, em consonância com a linha de raciocínio que já indicamos, que Kant poderia ter explorado de forma mais produtiva as consequências da filosofia crítica com seu fenomenalismo inerente, exposta na Analítica Transcendental. Já que os objetos naturais haviam deixado de ser entes para se tornarem a unidade sistemática de dados sensíveis segundo conceitos-regras, nada impediria Kant de concluir que o interesse prático instaura uma perspectiva diferente sobre a sensibilidade, com seu discurso estruturante de ordem diversa. 0 idealismo kantiano, ao não pensar os conceitos como determinações das coisas em si, tornaria compatível os reclames da liberdade e da natureza, por estarem em domínios diferentes.

Não obstante, em vez disso, Kant parece ter optado por ontologizar sua moral na Dialética, ao conceber o poder causal de um agente moral no domínio dos entes considerados em si mesmos, afinal, por mais que o mundo inteligível seja um ponto de vista, não deixa de ser o ponto de vista segundo o qual nos pensamos como coisas em si. A filosofia moral torna-se incursão no transcendente destituido de significado para nós e este fato não se torna filosoficamente mais aceitável apenas pela ressalva de que nosso interesse não é teórico. Continuamos tendo um discurso vazio e, na verdade, ininteligivel, quando falamos em atos e objetos não sensiveis. Já no Cânon, Kant não parece disposto a pagar tamanho preço pela compatibilização entre liberdade e natureza, preferindo pensar apenas a lei como pura, e não o interesse moral.

Para ser uma causa eficiente, o arbítrio moral é naturalizado e sua liberdade, por isso mesmo, relativizada. Agora, o preço a ser pago diz respeito à teoria da imputabilidade moral. 


\section{LIBERDADE E NATUREZA NAS PRINCIPAIS OBRAS DA FILOSOFIA PRÁTICA KANTIANA}

$\mathrm{Na}$ Fundamentação da metafísica dos costumes, Kant parece ter se decidido pelo preço a ser pago pela posição adotada na Dialética, uma vez cunhado em sua integridade o conceito-chave de sua moral: a autonomia. Como esta torna impossivel a sobreposição de motivos empíricos para que a lei moral seja vista como eficiente, o que tínhamos visto acontecer no Cânon, Kant se deixa seduzir pela distinção entre um mundo inteligivel e um mundo sensivel: "E assim são possiveis os imperativos categóricos [morais], porque a idéia da liberdade faz de mim um membro do mundo inteligível" (KANT, 2000, p. 103).

No entanto, a mesma obra começa a apresentar a doutrina kantiana do sentimento moral, como um efeito subjetivo/sensível da lei da razão pura. Este sentimento parece vir a título de explicar a motivação moral sensivelmente, mas fora do domínio natural:

Para que um ser, ao mesmo tempo racional e afetado pelos sentidos queira aquilo que só a razão Ihes prescreve como dever, é preciso sem dúvida uma faculdade da razão que inspire um sentimento de prazer ou de satisfação no cumprimento do dever, e, por conseguinte, que haja uma causalidade da razão que determine a sensibilidade conforme aos seus principios (KANT, 2000, p. 113).

Em suma, Kant explica aqui a motivação moral como o despertar de um sentimento quando a razão apresenta a validade da lei moral. Seria próprio do discurso moral a atribuição de um poder de afecção sensivel à validade racional, ou seja, o fato de um evento ser atribuído a algo que não é evento. Mas, ainda na Fundamentação, Kant insiste em pensar a validade que exerce efeito sobre nós em termos ontológicos, como atividade numênica: a moralidade "interessa porque é válida para nós como homens, pois que nasceu da nossa vontade, como inteligência, e, portanto, do nosso verdadeiro eu; mas o que pertence ao simples fenômeno é necessariamente subordinado pela razão à constituição da coisa em si mesma" (KANT, 2000, p. 113).

$\mathrm{Na}$ Crítica da razão prática, Kant (1997b) defende logo no prefácio que se faça um uso suprassensivel das categorias com intenção prática. No decorrer da obra, capítulo II do Livro Segundo, ele dedica uma seção inteira ao tema: "VII - Como é possivel conceber uma extensão da razão pura, sob o aspecto prático, sem ao mesmo tempo ampliar assim o seu conhecimento, enquanto especulativo?". Kant acredita agora ser possivel que a razão em seu uso prático conceda realidade a objetos suprassensiveis, desde que, teoricamente, eles possam ser pensados:

Esta realidade proporciona-a a razão pura prática e, a este respeito, a razão teórica nada mais tem a fazer do que pensar simplesmente estes objetos através de categorias, o que, 
como demonstramos claramente, pode muito bem fazer-se sem precisar de intuição (sensivel ou suprasensivel), porque as categorias têm a sua sede e origem no entendimento puro, independentemente e antes de toda a intuição, simplesmente enquanto faculdade de pensar, e porque elas designam sempre apenas um objeto em geral, seja qual for a maneira como ele nos possa ser dado (KANT, 1997b, p. 115).

Pois bem, para que o argumento de Kant funcione temos que conceber a independência da atividade de pensar com respeito à sensibilidade. Entretanto, a discursividade, com suas categorias, não é atribuível a qualquer intelecto, mas, por definição, apenas àquele que não é intuitivo, isto é, àquele para o qual o pensamento não é a intuição criadora de um todo, mas sim a síntese de uma multiplicidade vinda de fora dele para a formação de um complexo. 0 intelecto que não é criador, em outras palavras, precisa de uma receptividade que Ihe trará os dados sobre os quais aplicará sua atividade de síntese.

Em suma, não é possível conceber um intelecto discursivo sem sensibilidade e toda atividade sua resume-se necessariamente à síntese do múltiplo sensível. Seus conceitos nada mais são do que regras para tal atividade. Daí que as categorias sejam, sim, anteriores e independentes dos dados empíricos, mas não são concebíveis sem aplicação sensível. A insistência de Kant pelo contrário parece ser um mero fruto de seu temor de sucumbir ao mesmo erro do Cânon: a naturalização da moralidade com a consequente derrocada na heteronomia. Neste sentido, por mais que a Crítica da razão prática desenvolva a teoria da motivação moral sensível baseada no respeito ("a própria moralidade, subjetivamente considerada como móbil" (KANT, 1997b, p. 91), o autor mantém-se preso à dicotomia natureza ou transcendência.

$\mathrm{Na}$ Metafísica dos costumes, encontramos justamente o sentimento moral como "receptividade do livre-arbítrio para ser movido pela razão pura prática e sua lei" (KANT, 2000, p. 177). Podemos dizer que, nesta obra, o autor, definitivamente, reconhece a importância de um domínio sensivel prático. Kant (2000) nos afirma expressamente admitir um paralelo entre a aplicabilidade sensível dos princípios teóricos e dos práticos. Assim, a metafísica dos costumes será aplicada à antropologia moral. No entanto, o amadurecimento do sentimento moral em uma teoria da aplicabilidade sensivel dos princípios a priori práticos não significa o abandono da parte de Kant do apelo ao mundo inteligível para tornar concebível a liberdade.

Na Metafísica dos costumes, o arbítrio é a faculdade de desejar "unida à consciência de ser capaz de produzir o objeto mediante a ação" (KANT, 2000, p. 177).

0 arbítrio é livre quando "pode ser determinado pela razõo pura" (KANT, 2000, p. 21). A liberdade é afirmada como conceito transcendente para a filosofia teórica e realidade comprovada para a filosofia prática. Trilhando este caminho, na sequência, Kant (2000, p. 32) ainda caracteriza o livre-arbítrio como "objeto suprassensível" e, por vezes, se refere ao homem livre como "homo noumenon". 
Podemos sugerir então, a título de considerações finais que, por mais que Kant tenha se preocupado progressivamente com a aplicabilidade sensivel do discurso prático, ele jamais deixou de estender a moralidade ao reino da transcendência, porque julgava que, do contrário, subverteria o sentimento moral em fundamento da moralidade, em vez de tomá-lo verdadeiramente como receptividade à racionalidade pura, o que implicaria em uma moral heterônoma. Quem pretenda excluir o eu numênico da filosofia kantiana em nome da própria coerência de sua teoria da discursividade tem pela frente, portanto, um árduo trabalho, mas podemos aqui fazer algumas indicações do caminho pelo qual optaríamos. Em primeiro lugar, nos recusaríamos a pensar qualquer objeto ou atividade do sujeito para além da temporalidade.

Em segundo lugar, distinguiríamos entre a atividade temporal e as regras conceituais envolvidas nas mesmas. Em seguida, observaríamos que o tempo lógico no qual elaboramos a ordem de razões que justifica a validade das regras não exclui o tempo histórico no qual se dá a atividade conforme a regras de primeira ou segunda ordem.

Parece que Kant nos diria então que ainda haveria um problema: como explicaríamos uma ação a partir da simples receptividade à validade de uma regra, isto é, com um primeiro começo. Ora, neste caso, responderiamos simplesmente que não se trata do que temos a fazer aqui. Não se trata de explicar uma ação como acontecimento natural, mas de agir, sendo que, da mesma forma que a causalidade natural (sem um primeiro começo) só se justifica por ser condição de possibilidade da objetividade natural, a causalidade pela liberdade (com um primeiro começo) é condição de possibilidade da objetividade prática. Em suma, o arbítrio não precisa ser numênico para ser livre, basta que não seja natural.

\section{Kant and the place of free will}

Abstract: This text aims to present some analyzes on the concept of free will in Kantian philosophy. The concept arises immediately in the context of the solution of the antinomies in the Critique of Pure Reason, where it addresses the issue from an initial distinction internal to the concept of causality: causality according to nature and causality through freedom. The causality for freedom, the main object of this reflection, refers to the possibility of a first beginning in the causal order or, in other words, to the possibility that a cause is not, in turn, also an effect, being then unconditioned. It is in this perspective that the theme of free will for Kant is inserted

Keywords: Freedom. Free will. Causality. Antinomies. Nature.

\section{REFERÊNCIAS}

KANT, I. Kant's gesammelte schriften. Berlin und Leipzig: Walter de Gruyter \& Co., 1926. KANT, I. Werke in zwölf bande. Ed. W. Weischedel. Frankfurt: Suhrkamp, 1991. 
KANT, I. La metafísica de las costumbres. Traducción Adela Cortina Orts y Jesus Conill Sancho. Madrid: Tecnos, 1994.

KANT, I. Crítica da razão pura. Tradução Manuela Pinto dos Santos e Alexandre Fradique Morujão. 4. ed. Lisboa: Calouste Gulbenkian, 1997a.

KANT, I. Crítica da razão prática. Tradução Artur Morão. Lisboa: Edições 70, $1997 b$.

KANT, I. Fundamentação da metafísica dos costumes. Tradução Paulo Quintela. Lisboa: Edições 70, 2000.

Recebido em julho de 2018. Aprovado em outubro de 2018. 